\title{
What Factors Define Limb Salvage or Amputation Surgery in Osteosarcoma of the Upper Extremities?
}

\author{
MARIA T. HUAYLLANI ${ }^{1}$, DAVID J. RESTREPO ${ }^{1}$, DANIEL BOCZAR ${ }^{1}$, ANDREA SISTI ${ }^{1}$, AARON C. SPAULDING ${ }^{2}$, \\ ALEXANDER S. PARKER ${ }^{3}$, OSCAR J. MANRIQUE ${ }^{4}$, XIAONA LU ${ }^{5}$, BENJAMIN K. WILKE ${ }^{1}$ and ANTONIO J. FORTE ${ }^{1}$ \\ ${ }^{1}$ Division of Plastic Surgery, Mayo Clinic, Jacksonville, FL, U.S.A.; \\ ${ }^{2}$ Department of Health Science Research, Mayo Clinic, Jacksonville, FL, U.S.A.; \\ ${ }^{3}$ University of Florida, College of Medicine, Jacksonville, FL, U.S.A.; \\ ${ }^{4}$ Division of Plastic Surgery, Mayo Clinic, Rochester, MN, U.S.A.; \\ ${ }^{5}$ Division of Plastic Surgery, Yale School of Medicine, New Haven, CT, U.S.A.
}

\begin{abstract}
Background/Aim: Controversy exists between performing limb salvage or amputation to treat osteosarcoma of the upper extremities. Our aim was to review the characteristics associated with limb amputation due to osteosarcoma of the upper extremities. Patients and Methods: A descriptive study was performed by querying the National Cancer Database from January 1, 2004 to December 31, 2015. Statistical analysis was performed using chi-squared test and a multivariate logistic regression model. Results: A total of 777 patients diagnosed with osteosarcoma of the upper extremities who underwent surgery met the inclusion criteria. Patients between 61 and 80 years were less likely to undergo limb amputation. Moreover, facilities located in the South Atlantic region, and stage IV of the disease were factors independently positively associated with amputation. Conclusion: Patients in facilities located in the South Atlantic region and those with stage IV disease were more likely to undergo amputation.
\end{abstract}

Osteosarcoma is the most common bone tumor, with a global incidence of three cases per million per year (1). Osteosarcomas in the upper extremities are rare, occupying the third most common location of primary osteosarcoma after the distal femur and the proximal tibia (2).

Due to the aggressive pattern of this tumor, the standard treatment has historically been amputation; however, the effectiveness of chemotherapy has resulted in improvement

Correspondence to: Antonio J. Forte, MD, $\mathrm{PhD}$, MS, Division of Plastic Surgery, Mayo Clinic, 4500 San Pablo Rd, Jacksonville, FL 32224, U.S.A. Tel.: +1 9049532073, Fax: +1 9049537368, e-mail: ajvforte@yahoo.com.br

Key Words: Osteosarcoma, upper extremities, limb salvage, amputation, NCDB. of survival rates and has allowed limb-salvage resection (3). Different factors decide the type of surgery to be performed. A limb-salvage surgery is preferred when it is possible to obtain negative margins through a wide-margin resection (4). Relative and absolute contraindications to limb-salvage surgery, such as neurovascular compromise, pathological fracture with hematoma extended beyond compartment boundaries, errant biopsy placement, tissue coverage problems, or severe infections in the surgical site, direct the decision to performing an amputational surgery (5). To date, as far as we are aware, no study has described other characteristics that may influence the type of surgery chosen for treatment of osteosarcomas of the upper extremities. This study describes and identifies patient, facility, and tumor characteristics that determine the type of surgical treatment of patients with osteosarcoma of the upper extremities in the United States.

\section{Patients and Methods}

A retrospective cohort study was conducted by querying the National Cancer Database (NCDB) (6) for cases of osteosarcoma in the upper extremities diagnosed and treated between January 1, 2004, and December 31, 2015.

Inclusion and exclusion criteria. We excluded patients with diagnoses other than osteosarcoma, as well as those with osteosarcoma in locations other than the upper extremities. Additionally, patients who did not undergo surgery, or had missing data related to the type of surgery performed were excluded. Finally, 777 patients diagnosed with osteosarcoma in the upper extremities were considered for the study.

Variables. Independent variables included patient characteristics (age, sex, race, comorbidities, Hispanic origin, insurance, income, and education), facility characteristics (facility type, facility location, and setting), and tumor characteristics [tumor site, size, and American Joint Committee on Cancer (AJCC) 7th edition stage 
(7)]. The dependent variable was type of surgery, including local resection with limb salvage or amputation of the limb. All missing values were excluded for the analysis.

Statistical analysis. A chi-squared analysis was performed to compare characteristics between patients who underwent tumor resection with limb salvage with those who underwent amputation of the limb. A multivariate logistic regression was performed to analyze the factors associated with amputation of the limb as surgical management. A value of $p<0.05$ was considered significant for the analysis. All data were analyzed using SPSS, version 25 (IBM, Armonk, NY, USA) software.

\section{Results}

A total of $125(16.1 \%)$ patients with osteosarcoma of the upper extremity had an amputation of the limb and 652 (83.9\%) patients underwent a local resection with limb salvage (Table I). Most of the patients with osteosarcoma of the upper extremity who underwent an amputation lived in areas where a high rate of people did not graduate from high school (38.4\%), were White $(71.2 \%)$ men $(68 \%)$ younger than 21 years old $(41.6 \%)$ with government insurance $(48.8 \%)$ and an income between $\$ 38,000$ and $\$ 47,999$. Regarding facility characteristics, most were treated in Academic/Research programs $(20.0 \%)$ and belonged to metropolitan areas $(85.6 \%)$. Most tumors were located in the hand (92\%), larger than $8 \mathrm{~cm}(66.4 \%)$, and in stage II of disease $(45.6 \%)$.

Patients diagnosed between 61 and 80 years of age were less likely to undergo amputation of the limb [odds ratio $(\mathrm{OR})=0.04 ; 95 \% \mathrm{CI}=0.01-0.42 ; p=0.01]$ when compared to patients between 21 and 40 years old. On the other hand, patients with stage IV of the disease (OR=7.45; 95\% $\mathrm{CI}=1.22-45.54 ; p=0.03)$ and treated in facilities located in the South Atlantic (OR=8.51; 95\% CI=1.10-65.86; $p=0.04)$ were more likely to have undergone an amputational surgery when compared to patients who underwent local resection with limb salvage (Table II). No statistical differences in sex, race, comorbidities, Hispanic origin, insurance, income, education, facility type, setting, tumor site, and tumor size were found.

\section{Discussion}

Osteosarcoma treatment consists of a combination of surgery and chemotherapy (8). A study by Simon et al. suggested the safety of performing a conservative surgery with limb salvage rather than amputation in patients with high-grade osteosarcoma (9). However, there are still controversies in the long-term outcomes regarding the type of surgery that should be performed (10). For instance, Rougraff et al. (11) reported a higher rate of local recurrence in patients with limb salvage even when they noticed that survival of patients treated with limb salvage or amputation was not different. On the other hand, Yin et al. (12) and Li et al. (13) found no significant difference in risk of local recurrence and 5-year overall survival between these types of surgery. Chemotherapy has helped to increase the survival of patients with these types of bone tumor (14), and as a result, limb salvage surgeries are commonly preferred thanks to the advantages after tumor resection in preserving functionality of the limb. To our knowledge, the factors associated with the decision between limb amputation and limb salvage in osteosarcoma of the upper extremities have not been analyzed. Our study found a greater likelihood for limb salvage surgery in patients between 61 and 80 years compared to younger patients. The type of treatment for elderly patients requires special evaluation because of existing comorbidities that may influence the clinical course and prognosis (15). Additionally, as metastasis is more common in this age group, most surgeons try to preserve the limb, reserving amputation for curative intent or palliative reasons. The surgeons' decision in this patient group was probably based on careful riskbenefit evaluation and evidence of studies supporting the use of limb-salvage surgery (16).

Our study also found that stage was the only tumor factor that influenced the type of surgery. We found that patients with osteosarcomas of AJCC disease stage IV had a higher likelihood of amputation over limb salvage. This is most likely related to the presence of metastasis at late stages of the disease. However, in the meta-analysis conducted by Xiaojuan $\mathrm{Li}$ et al. of patients with osteosarcomas in Enneking stage IIA and IIB, no significant difference between the two surgery methods was found; however, they found a high rate of local recurrence in five of 17 studies and a lower rate of metastatic occurrence in four of 17 studies in patients who underwent limb salvage surgery compared to amputation (13). Enneking staging system for malignant mesenchymal tumors considers surgical grade (G1, G2, G3), local extent (T, T1, T2), and presence or absence of metastasis (M0, M1) (17). Stage IIA and IIB include highgrade tumors without metastasis which are more likely to invade surrounding host tissue. We believe that other factors related to the biology of the disease, such as genomic complexity and instability and intra- and intertumoral heterogeneity, may influence the discrepancies in the outcomes between studies (18). For that reason, we suggest that further studies comparing the recurrence and survival between types of surgeries for osteosarcoma patients should be conducted. In addition, since the benefits of performing limb-salvage surgeries are unclear, the decision on the type of surgery in osteosarcoma of the upper extremities should be guided based on the patient response to chemotherapy, although the benefit from performing a limb-salvage surgery in patients with AJCC disease stage IV seems to be secure.

We did not find any association with sex, race, Hispanic origin, insurance, income, education, facility type, setting, 
Table I. Patient demographics and tumor characteristics.

\begin{tabular}{|c|c|c|c|c|c|c|}
\hline & & \multicolumn{4}{|c|}{ Surgical treatment } & \multirow{3}{*}{$p$-Value } \\
\hline & & \multicolumn{2}{|c|}{ Local resection with limb salvage } & \multicolumn{2}{|c|}{ Amputation of limb } & \\
\hline & & $\mathrm{n}$ & $\%$ & $\mathrm{n}$ & $\%$ & \\
\hline Total & & 652 & 830.9 & 125 & 160.1 & \\
\hline \multirow[t]{5}{*}{ Age } & $<21$ Years & 311 & 470.7 & 52 & 410.6 & 0.03 \\
\hline & 21-40 Years & 172 & 260.4 & 42 & 330.6 & \\
\hline & 41-60 Years & 101 & 150.5 & 13 & 100.4 & \\
\hline & $61-80$ Years & 61 & 90.4 & 13 & 100.4 & \\
\hline & $\geq 81$ Years & 7 & 10.1 & 5 & 40.0 & \\
\hline \multirow[t]{2}{*}{ Sex } & Male & 359 & 550.1 & 85 & 680.0 & 0.01 \\
\hline & Female & 293 & 440.9 & 40 & 320.0 & \\
\hline \multirow[t]{4}{*}{ Race } & Race & 507 & 770.8 & 89 & 710.2 & \\
\hline & White & 115 & 170.6 & 33 & 260.4 & 0.03 \\
\hline & Others & 30 & 40.6 & 3 & 20.4 & \\
\hline & Missing data & & & & & \\
\hline \multirow[t]{2}{*}{ Comorbidities } & No & 590 & 900.5 & 114 & 910.2 & 0.80 \\
\hline & Yes & 62 & 90.5 & 11 & 80.8 & \\
\hline \multirow[t]{3}{*}{ Origin } & Non-Spanish, non-Hispanic & 540 & 820.8 & 102 & 810.6 & 0.32 \\
\hline & Hispanic, Spanish origin & 81 & 120.4 & 20 & 16 & \\
\hline & Missing data & 31 & 40.8 & 3 & 20.4 & \\
\hline \multirow[t]{4}{*}{ Insurance } & Not insured & 24 & 30.7 & 8 & 60.4 & $<0.001$ \\
\hline & Private & 400 & 610.3 & 54 & 430.2 & \\
\hline & Government & 207 & 310.7 & 61 & 480.8 & \\
\hline & Missing data & 21 & 30.2 & 2 & 10.6 & \\
\hline \multirow[t]{5}{*}{ Income } & $\geq \$ 63,000$ & 204 & 310.3 & 27 & 210.6 & 0.08 \\
\hline & $\$ 48,000-\$ 62,999$ & 163 & 250.0 & 31 & 240.8 & \\
\hline & $\$ 38,000-\$ 47,999$ & 137 & 210.0 & 37 & 290.6 & \\
\hline & $<\$ 38,000$ & 142 & 210.8 & 28 & 220.4 & \\
\hline & Missing data & 6 & 0.9 & 2 & 10.6 & \\
\hline \multirow[t]{5}{*}{ Education ${ }^{\ddagger}$} & $<7 \%$ & 154 & 230.6 & 25 & 20 & 0.01 \\
\hline & $7-12.9 \%$ & 192 & 290.4 & 26 & 200.8 & \\
\hline & $13-20.9 \%$ & 155 & 230.8 & 48 & 380.4 & \\
\hline & $\geq 21 \%$ & 145 & 220.2 & 24 & 190.2 & \\
\hline & Missing data & 6 & 00.9 & 2 & 10.6 & \\
\hline \multirow[t]{4}{*}{ Facility type } & Community Cancer Programs & 39 & 60.0 & 8 & 60.4 & 0.44 \\
\hline & Academic/Research Program & 110 & 160.9 & 25 & 20 & \\
\hline & Integrated Network Cancer Program & 23 & 30.5 & 2 & 10.6 & \\
\hline & Missing data & 480 & 730.6 & 90 & 72 & \\
\hline \multirow[t]{7}{*}{ Facility location } & New England and Middle Atlantic & 28 & 40.3 & 6 & 40.8 & 0.81 \\
\hline & South Atlantic & 33 & 50.1 & 10 & 8 & \\
\hline & East Central (North and South) & 50 & 70.7 & 8 & 60.4 & \\
\hline & West Central (North and South) & 26 & 40.0 & 6 & 40.8 & \\
\hline & Mountain & 15 & 20.3 & 2 & 10.6 & \\
\hline & Pacific & 20 & 30.1 & 3 & 20.4 & \\
\hline & Missing data & 480 & 730.6 & 90 & 72 & \\
\hline \multirow[t]{4}{*}{ Setting } & Metropolitan & 523 & 800.2 & 107 & 850.6 & 0.15 \\
\hline & Urban & 95 & 140.6 & 10 & 8 & \\
\hline & Rural & 18 & 20.8 & 4 & 30.2 & \\
\hline & Missing data & 16 & 20.5 & 4 & 30.2 & \\
\hline \multirow[t]{2}{*}{ Tumor site } & Hand & 610 & 930.6 & 115 & 92 & 0.52 \\
\hline & Forearm, arm and shoulder & 42 & 60.4 & 10 & 8 & \\
\hline Tumor size & $\leq 8 \mathrm{~cm}$ & 249 & 380.2 & 25 & 20 & $<0.001$ \\
\hline & $>8 \mathrm{~cm}$ & 321 & 490.2 & 83 & 660.4 & \\
\hline & Missing data & 82 & 120.6 & 17 & 130.6 & \\
\hline Stage $^{a}$ & I & 133 & 200.4 & 15 & 12 & 0.01 \\
\hline & II & 305 & 460.8 & 57 & 450.6 & \\
\hline & III & 20 & 30.1 & 5 & 4 & \\
\hline & IV & 74 & 110.3 & 29 & 230.2 & \\
\hline & Missing data & 120 & 180.4 & 19 & 150.2 & \\
\hline
\end{tabular}

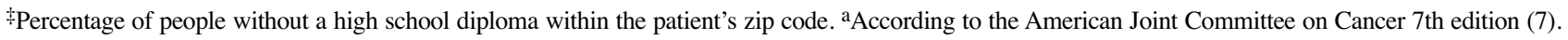


Table II. Multivariable logistic regression model for amputation of the limb.

\begin{tabular}{|c|c|c|c|}
\hline & OR & $\mathrm{CI}$ & $p$-Value \\
\hline \multicolumn{4}{|l|}{ Age } \\
\hline 21-40 Years & $1.00 *$ & & \\
\hline 41-60 Years & 0.15 & $0.01-5.44$ & 0.30 \\
\hline $61-80$ Years & 0.04 & $0.01-0.42$ & 0.01 \\
\hline$\geq 81$ Years & 0.10 & $0.01-1.07$ & 0.06 \\
\hline \multicolumn{4}{|l|}{ Gender } \\
\hline Male & $1.00 *$ & & \\
\hline Female & 0.55 & $0.15-1.97$ & 0.36 \\
\hline \multicolumn{4}{|l|}{ Race } \\
\hline White & $1.00 *$ & & \\
\hline Other & 1.70 & $0.28-10.17$ & 0.56 \\
\hline No & $1.00 *$ & & \\
\hline \multicolumn{4}{|l|}{ Comorbidities } \\
\hline Yes & 0.57 & $0.11-2.88$ & 0.49 \\
\hline \multicolumn{4}{|l|}{ Origin } \\
\hline Non-Spanish, non-Hispanic & $1.00^{*}$ & & \\
\hline Hispanic, Spanish origin & 0.25 & $0.02-3.92$ & 0.32 \\
\hline \multicolumn{4}{|l|}{ Insurance } \\
\hline Not insured & $1.00^{*}$ & & \\
\hline Private & 0.89 & $0.05-15.57$ & 0.94 \\
\hline Government & 0.51 & $0.02-10.70$ & 0.67 \\
\hline \multicolumn{4}{|l|}{ Income } \\
\hline$\geq \$ 63,000$ & $1.00^{*}$ & & \\
\hline$\$ 48,000-\$ 62,999$ & 0.94 & $0.16-5.65$ & 0.94 \\
\hline$\$ 38,000-\$ 47,999$ & 1.00 & $0.13-7.89$ & $>0.99$ \\
\hline$<\$ 38,000$ & 0.35 & $0.03-4.38$ & 0.42 \\
\hline \multicolumn{4}{|l|}{ Education $\ddagger$} \\
\hline$<7 \%$ & $1.00 *$ & & \\
\hline $7-12.9 \%$ & 1.37 & $0.19-9.68$ & 0.75 \\
\hline $13-20.9 \%$ & 5.47 & $0.60-50.08$ & 0.13 \\
\hline$\geq 21 \%$ & 1.54 & $0.08-31.06$ & 0.78 \\
\hline \multicolumn{4}{|l|}{ Facility type } \\
\hline Community Cancer Programs & $1.00 *$ & & \\
\hline Academic/Research Program & 2.75 & $0.53-14.15$ & 0.23 \\
\hline Integrated Network Cancer Program & 0.22 & $0.01-6.11$ & 0.37 \\
\hline \multicolumn{4}{|l|}{ Facility location } \\
\hline South Atlantic & 8.51 & $1.10-65.86$ & 0.04 \\
\hline East Central (North and South) & 2.40 & $0.33-17.42$ & 0.39 \\
\hline West Central (North and South) & 2.83 & $0.32-24.93$ & 0.35 \\
\hline Mountain & 6.89 & $0.56-84.49$ & 0.13 \\
\hline Pacific & 8.14 & $0.81-81.88$ & 0.08 \\
\hline \multicolumn{4}{|l|}{ Setting } \\
\hline Metropolitan & $1.00 *$ & & \\
\hline Urban & 1.24 & $0.27-5.74$ & 0.78 \\
\hline Rural & 1.91 & $0.05-73.69$ & 0.73 \\
\hline \multicolumn{4}{|l|}{ Tumor site } \\
\hline Hand & $1.00 *$ & & \\
\hline Forearm, arm and shoulder & 2.35 & $0.25-22.19$ & 0.46 \\
\hline \multicolumn{4}{|l|}{ Tumor size } \\
\hline$\leq 8 \mathrm{~cm}$ & $1.00 *$ & & \\
\hline$>8 \mathrm{~cm}$ & 2.79 & $0.79-9.89$ & 0.11 \\
\hline \multicolumn{4}{|l|}{ Stage ${ }^{a}$} \\
\hline I & $1.00 *$ & & \\
\hline II & 0.78 & $0.16-3.68$ & 0.75 \\
\hline III & 0.81 & $0.04-16.69$ & 0.89 \\
\hline IV & 7.45 & $1.22-45.54$ & 0.03 \\
\hline
\end{tabular}

OR: Odds ratio; CI: confidence interval. *Reference value. ₹Percentage of people without a high school diploma within the patient's zip code. aAccording to the American Joint Committee on Cancer 7th edition (7). tumor site, and tumor size in performing either type of surgery, perhaps due to the low frequency of patients with osteosarcomas of the upper extremities.

A few limitations of this retrospective database study should be noted. In particular, our results were dependent on the information compiled in the NCDB, which was not always complete. In an effort to obtain the most accurate results possible, we excluded those with missing information; although the sample size decreased, this study evaluated the highest number of patients with osteosarcoma of the upper extremities to date. Despite these limitations, we believe this study reports a valuable analysis of the factors associated with type of surgery performed.

In conclusion, our study found that osteosarcomas of the upper extremities are more likely to be surgically treated by amputation of the limb rather than limb-salvage surgery when they have AJCC disease stage IV. This study highlights the importance of disease stage in the surgical treatment of osteosarcoma of the upper extremities.

\section{Conflicts of Interest}

The Authors have no conflicts of interest to declare regarding this study.

\section{Authors' Contributions}

MTH, DJR and AJF had full access to all of the data in the study and take responsibility for the integrity of the data and the accuracy of the data analysis. Study concept and design: MTH, AJF, ACS. Acquisition, analysis, or interpretation of data: MTH, ASP, AJF. Drafting of the article: MTH, DJR, DB, AS. Critical revision of the article for important intellectual content: BR, SLM, MTH, ACS and AJF. Study supervision: AJF.

\section{Acknowledgements}

This study was supported in part by the Mayo Clinic Robert D. and Patricia E. Kern Center for the Science of Health Care Delivery, and by the Mayo Clinic Center for Individualized Medicine.

\section{References}

1 Picci P: Osteosarcoma (osteogenic sarcoma). Orphanet J Rare Dis 2: 6, 2007. PMID: 17244349. DOI: 10.1186/1750-1172-2-6

2 Morsy AM, Abdelgawad MI, Ahmed BM, Rezk KM, Aboelgheit AM, Ramadan IK, Kamel HEM, Fouad DM, Herdan RA, Shabaan SH and Eltyb HA: Pediatric osteosarcoma of extremities: A 15-year experience from a tertiary care cancer center in upper egypt. J Pediatr Hematol Oncol, 2019. PMID: 30629005. DOI: 10.1097/0.0000000000001407

3 Ritter J and Bielack SS: Osteosarcoma. Ann Oncol 21(Suppl 7): vii320-325, 2010. PMID: 20943636. DOI: 10.1093/annonc/ mdq276

4 Mavrogenis AF, Lenze U, Rechl H, Letson GD and Ruggieri P: Recent developments in the surgical treatment of bone tumors and their impact on quality of life. Sarcoma 2013: 826432, 2013. PMID: 23935391. DOI: 10.1155/2013/826432 
5 Jauregui JJ, Nadarajah V, Munn J, Pivec R, Kapadia BH, Lerman DM and Maheshwari AV: Limb salvage versus amputation in conventional appendicular osteosarcoma: A systematic review. Indian J Surg Oncol 9(2): 232-240, 2018. PMID: 29887707. DOI: 10.1007/s13193-018-0725-y

6 Vega SJ, Bossert RP and Serletti JM: Improving outcomes in bilateral breast reconstruction using autogenous tissue. Ann Plast Surg 56(5): 487-490; discussion 490-481, 2006. PMID: 16641622. DOI: 10.1097/01.0.0000205236.88313.10

7 Edge S BD, Compton CC, Fritz AG, Greene FL and Trotti A: Ajcc cancer staging manual seventh edition. Springer (ed.). 2010 .

8 Misaghi A, Goldin A, Awad M and Kulidjian AA: Osteosarcoma: A comprehensive review. Sicot J 4: 12, 2018. PMID: 29629690. DOI: $10.1051 / \operatorname{sicotj} / 2017028$

9 Simon MA, Aschliman MA, Thomas N and Mankin HJ: Limbsalvage treatment versus amputation for osteosarcoma of the distal end of the femur. J Bone Joint Surg Am 68(9): 1331-1337, 1986. PMID: 3465732.

10 Chen Y, Yu XC, Xu SF, Xu M and Song RX: Impacts of tumor location, nature and bone destruction of extremity osteosarcoma on selection of limb salvage operative procedure. Orthop Surg 8(2): 139-149, 2016. PMID: 27384722. DOI: 10.1111/0.12237

11 Rougraff BT, Simon MA, Kneisl JS, Greenberg DB and Mankin $\mathrm{HJ}$ : Limb salvage compared with amputation for osteosarcoma of the distal end of the femur. A long-term oncological, functional, and quality-of-life study. J Bone Joint Surg Am 76(5): 649-656, 1994. PMID: 8175811. DOI: $10.2106 / 000$ 04623-199405000-00004

12 Yin K, Liao Q, Zhong D, Ding J, Niu B, Long Q and Ding D: Meta-analysis of limb salvage versus amputation for treating high-grade and localized osteosarcoma in patients with pathological fracture. Exp Ther Med 4(5): 889-894, 2012 PMID: 23226744. DOI: 10.3892/0.2012.685
13 Li X, Zhang Y, Wan S, Li H, Li D, Xia J, Yuan Z, Ren M, Yu S, Li S, Yang Y, Han L and Yang Z: A comparative study between limb-salvage and amputation for treating osteosarcoma. J Bone Oncol 5(1): 15-21, 2016. PMID: 26998422. DOI: 10.1016/ j.0.2016.01.001

14 Pradhan A, Reddy KI, Grimer RJ, Abudu A, Tillman RM, Carter SR and Jeys L: Osteosarcomas in the upper distal extremities: Are their oncological outcomes similar to other sites? Eur J Surg Oncol 41(3): 407-412, 2015. PMID: 25442503. DOI: 10.1016/ j.0.2014.11.038

15 Kumar R, Kumar M, Malhotra K and Patel S: Primary osteosarcoma in the elderly revisited: Current concepts in diagnosis and treatment. Curr Oncol Rep 20(2): 13, 2018. PMID: 29492676. DOI: 10.1007/s11912-018-0658-1

16 Harting MT, Lally KP, Andrassy RJ, Vaporciyan AA, Cox CS, Jr., Hayes-Jordan A and Blakely ML: Age as a prognostic factor for patients with osteosarcoma: An analysis of 438 patients. J Cancer Res Clin Oncol 136(4): 561-570, 2010. PMID: 19784847. DOI: 10.1007/s00432-009-0690-5

17 Jawad MU and Scully SP: In brief: Classifications in brief: Enneking classification: Benign and malignant tumors of the musculoskeletal system. Clin Orthop Relat Res 468(7): 20002002, 2010. PMID: 20333492. DOI: 10.1007/s11999-010-13157

18 Kansara M, Teng MW, Smyth MJ and Thomas DM: Translational biology of osteosarcoma. Nat Rev Cancer 14(11): 722-735, 2014. PMID: 25319867. DOI: $10.1038 / \mathrm{nrc} 3838$
Received October 29, 2019

Revised November 2, 2019

Accepted November 7, 2019 